\section{IJ $\$ E R$}

ISSN: 2149-5939
International Journal of Social Sciences and Education Research

Online, http://dergipark.gov.tr/ijsser

Volume: 1(1), 2015

\title{
Y kuşağı bakış açısıyla öğrenci sorunları ve çözüm önerileri: Isparta Meslek Yüksekokulu Örneği
}

\section{Student problems and solution proposals by generation Y Perspective: Isparta Voca- tional High School Case}

\author{
Pınar Göktaş1
}

\begin{abstract}
Received Date: $01 / 01 / 2015$
Accepted Date: $01 / 02$ / 2015

$\ddot{O}_{z}$

Hemen hemen aynı yıllarda doğmuş, ortak özelliklere sahip kişilerin oluşturduğu gruplar kuşak olarak tanımlanmaktadır. Kuşak sinıflandırılması; Gelenekselciler, Bebek Patlaması, X, Y ve Z Kuşağı olarak yapılmaktadır. Bu çalışmada 1980-1999 arası doğanları içeren Y kuşă̆ı bakış açısıyla öğrenci sorunları ele alınmıştır. Süleyman Demirel Üniversitesi Isparta Meslek Yüksekokulu’nda ögrrenim gören öğrencilerin görüşlerine göre bu sorunlar beyin firtınası yöntemiyle belirlenmiş, Balık kılçığı diyagramıyla analiz edilmiş ve neden nasıl ă̆aç diyagramı aracılığılyla çözüm önerileri sunulmuştur. Araştırmaya Süleyman Demirel Üniversitesi Isparta Meslek Yüksekokulu'ndaki yedi bölümün her birinden 50 'şer ögrenci katılmıştır. Yani toplamda 350 ögrenci ile araştırma yürütülmüştür. Araştırmadan elde edilen bulgular neticesinde Y kuşağı bakış açısıyla ögrenci sorunlarl ve çözüm önerilerinin üniversite yönetimiyle ve yerel yöneticilerle paylaşılması önerilmektedir. Böylece eğitimde kaliteyi geliştirmek amaçlanmaktadır. Araştırmanın önemi, ögrencilerin sorunlarının tespiti, ana problemlerin iyileştirilmesi ve diğer konularda da düzenleme ve geliştirme çalışmalarının toplam kalite yönetimi çerçevesinde uygulanmasıdır. Ayrıca bundan sonraki araştırmacıların bu alanda çalışmalar yapmasının önemli katkılar doğuracağı düşünülmektedir.
\end{abstract}

Anahtar sözcükler: Y kuşă̆̆, üniversite öğrenci problemleri, balık kılçı̆̆ı diyagramı, ăgaç diyagramı

\begin{abstract}
Almost born in the same year, the group of individuals with common characteristics can be defined as the generation. Generation classification is made as Traditionalists, the Baby Boomer, Gen X, Y and Z. As part of this research, student's problems were researched for the Y Generation who was born between 1980-1999. These problems have been identified with brain storming method, have been analysed with fishbone diagram and solution proposals have been presented by why-how tree diagram according to studens' view of Süleyman Demirel University Isparta Vocational High School. 50 student have been selected from each of the seven departments in other words a total of 350 students of Süleyman Demirel University Isparta Vocational High School participated in this research. As a result of findings obtained from this research, students' problems and solutions proposals by generation Y perspective should be shared with university management and local authorities so that the quality of education is expected to improve. The importance of this research is to identify the problems of students, to improve of the main problems and implementation of regulation and development works in other issues within the framework of total quality management. Also it would make important contributions if new researchers study about particularly the characteristics of generations in Turkey.
\end{abstract}

Keywords: Y generation, university student problems, fishbone diagram, tree diagram

Jel Classification: I21, I23

${ }^{1}$ Dr., Süleyman Demirel University, ISPARTA/TURKEY pinargoktas@sdu.edu.tr 
Göktaş, P. (2015). Y kuşağı bakış açısıyla öğrenci sorunları ve çözüm önerileri: Isparta Meslek Yüksekokulu

Örneği. International Journal of Social Sciences and Education Research, 1 (1), 197-206.

\section{Giriş}

"Kuşak" kelimesini Türk Dil Kurumu, "İnsanlık tarihinin başlangıcından günümüze kadar olan süreç içerisinde hemen hemen aynı yıllarda doğmuş, aynı dönemin koşullarını, dolayısıyla birbirine benzer problemleri, yazgıları yaşamış, benzer ödevlerle sorumlu olmuş kişilerin topluluğu” olarak tanımlamıştır (www.tdk.gov.tr). Kuşakların hangi tarih aralığında yer aldığıyla ilgili farklı görüşler olmasına rağmen genel anlamda Gelenekselciler, Bebek Patlaması, X, Y ve Z Kuşağı olarak sınıflandırılmaktadır. Bu çalışmada ele alınan Y kuşağı 1980 ile 1999 yılları arasında doğanları kapsamaktadır (Kyles, 2005: 54). Y kuşağının yaratıc1, özgürlüğüne düşkün, değişime odaklı, inatçı, dijital ve sanal dünyada rahat eden ve bireysel olma özellikleri dikkat çekmektedir (Uz, 2013). Kuşakların problemlerini tartışan Karl Mannheim(1893-1947), sosyal yapıyı ve düşünceleri anlamada kuşakların önemine dikkat çekmiştir (Parry ve Urwin, 2011: 81).

Günümüzde rekabetin olduğu her alanda kalite başlı başına bir değer konusu haline gelmiştir. Özellikle eğitim kurumlarında uygulanması son derece önemlidir. Çünkü kaliteli hizmet sunacak çalışanları yetiştirebilmek adına kaliteli bir eğitim hizmeti verilmelidir. Dolayısıyla eğitim-öğretim hizmetlerinin gerçekleşmesinde rolü olan tüm süreçlerde hata yapmamak ve yapılmış ise ortaya çıktığında hemen gidermek gerekmektedir. Yani süreçte sıfır hata esas olup çift yönlü bilgi akışı sağlanmalıdır (Baykara, 1999: 59). Bu bağlamda sorunların tespit edilmesinde ve çözümlenmesinde öğrencilerin görüşlerinin önemli olduğu düşünülmektedir. Eğitimde kaliteyi arttırmak için her üniversite öğrencisiyle, öğretim elemanlarıyla, yöneticisi ve personeliyle yani tüm çal1şanlarla kaliteyi hedeflemelidir. Bu hedef doğrultusunda nitelikli işgücü; kaliteli eğitim, donanımlı öğretim elemanları ve yeterli fiziki koşulların var olması ya da iyileştirilmesi ile sağlanabilmektedir.

Günümüzde ticaret, sanayi ve hizmet sektörlerinin gereksinim duyduğu alanlarında yeterli bilgi ve beceriye sahip ara elemanların yetiştirilmesi amacıyla kurulmuş olan meslek yüksekokullarının bu amaçlarını gerçekleştirebilmesinde meslek yüksekokullarında verilen eğitimin ihtiyaçlar doğrultusunda analiz edilip gerekli düzenlemelerin yapılması gerekmektedir (Alkan vd., 2014: 133). Bu bağlamda meslek yüksekokullarındaki mevcut sorunların ele alınıp çözümüne yönelik faaliyetlerin gerçekleştirilmesi önem arz etmektedir.

\section{2. Çalıșmanın amacı ve önemi}

Türkiye'de üniversiteyi kazanmak isteyen öğrencilerin sayıca fazla olması sebebiyle, devlet üniversitelerinin öğrenci bulamama gibi bir endişeleri bulunmamaktadır. Dolayısıyla üniversiteler arasında öğrenci sayıları ile ilgili bir rekabet söz konusu olmamakta ancak her bir üniversite, öğrencilerin ilk tercihi olmak açısından birbirleri ile rekabet halinde bulunmaktadır. Bu rekabette öne çıkmak ve diğer üniversitelerden farklılaşmak için yükseköğretim kurumlarının kaliteye önem vermeleri ve Y kuşağının görüşlerini dikkate almaları gerekmektedir (Türker, 2003: 11).

$\mathrm{Bu}$ araştırmada, Süleyman Demirel Üniversitesi Isparta Meslek Yüksekokulu'nda öğrenim gören Y kuşağında yer alan öğrencilerin sorunlarını belirlemek ve çözüm önerileri geliştirmek amaçlanmıştır. Çalışmanın önemi, öğrencilerin sorunlarının tespiti, ana problemlerin iyileştirilmesi ve diğer konularda da düzenleme ve geliştirme çalışmalarının Toplam Kalite Yönetimi çerçevesinde eğitimde kalite geliştirme araçları kullanılarak uygulanmasıdır. 
Göktaş, P. (2015). Student problems and solution proposals by generation Y perspective: Isparta Vocational High School Case. International Journal of Social Sciences and Education Research, 1 (1), 197-206.

\section{Araştırmanın yöntemi}

Bu çalışmada öğrencilerin aldığı eğitimden, öğretim elemanlarından, idari personelden, yönetimden, kampüs ve şehirden kaynaklı sorunları araştırılmıştır. Bu bağlamda Y kuşağında yer alan öğrencilerin sorunları hakkında görüşlerini almak üzere kalite geliştirme araçlarından "Beyin Fırtınası Tekniği”"ne başvurulmuş ve sonuçlar "Balık Kılçığı Diyagramı” ve "Neden Nasıl Ağaç Diyagramı" ile belirtilmiştir. Araştırmaya Süleyman Demirel Üniversitesi Isparta Meslek Yüksekokulu'ndaki 7 bölümden kolayda örneklemi yöntemiyle 50'şer öğrenci seçilerek toplamda 350 öğrenci katılmıştır (Evren: 5570). Cresswell (2013)'in önerdiği gibi veri toplama süreci yeni bakış ve özellikler ortaya çıkmadığında sonlandırılmıştır (Cresswell, 2013:189).

Uygulamada Y kuşağında yer alan öğrenciler sorunlarını ve çözüm önerilerine ilişkin düşüncelerini Beyin Fırtınası tekniği ile belirtmişlerdir. Beyin fırtınası tekniğinde öncelikle yöntem kuralları açıklanmıştır. Daha sonra öğrenciler fikirlerini serbestçe beyan etmişlerdir. Fikirler toplanıp yazılmış düzenlenmiş ve değerlendirilmiştir. Bunun sonucunda en iyi ve geçerli düşüncelerin tespiti yapılmıştır. Yapılan beyin fırtınası tekniğinin sonuçları kullanılarak balık kılçığı diyagramı için ana sorunlar saptanmıştır. Daha sonra ana sorunlara neden olan muhtemel alt nedenler sıralanarak 'Balık Kılçığı' diyagramında gösterilmiştir. Yani balık kılçı̆̆ı diyagramı ile süreçte ortaya çıan sonuçlar ve onlara etki eden temel sebeplerin tespit edilmesi sağlanmıştır (Mahiroğlu ve Buluç, 1999).

Balık Kılçığı Diyagramı, sebep-sonuç diyagramı ya da Ishikava diyagramı olarak da adlandırılmaktadır. Bu diyagram, bir problemin olası birçok sebebini belirmeye yardımcı olmaktadır. Beyin fırtınası tekniğiyle fikirler uygun kategorilere ayrılabilmektedir. Öncelikle problem tahtanın sağ ortasında yazılır. Yazının etrafında bir kutu çizilir ve buna yatay bir ok çizilir. Problemin sebeplerinin ana kategorileri beyin firtınası yapılarak belirlenir. Problemin bütün muhtemel sebepleri düşünülür. "Bu neden böyle oluyor?" diye sorulur. Araştırmacı tarafindan her fikir uygun kategoriye yazılır. Sebepler çeşitli kategoriler ile bağlantılı ise çeşitli yerlere yazılabilir. Her sebep için "Niçin böyle oluyor?" diye sorulur. Alt sebepler yazılır. "Niçin" sorusu sorulmaya devam edilir ve sebeplerin daha derin seviyeleri meydana getirilir (Tague, 2005: 247-248).

Belli bir amaca erişmek için Balık Kılçığı diyagramında belirlenen ana sorunlar iyileştirilmek üzere Şekil 1'de gösterildiği gibi ele alınmıştır.

Çözüm için izlenmesi gereken yollar sistematik bir şekilde' Neden Nasıl Ağaç Diyagramı'nda oluşturulmuştur. Balık kılçığı diyagramında belirlenen dört temel nedenin çözülmesine yönelik olarak "nasıll" sorusu sorulmuş ve Süleyman Demirel Üniversitesi Isparta Meslek Yüksekokulu'nda öğrenim gören Y kuşağı öğrencileri tarafından öneriler geliştirilmiştir. Ağaç diyagramı yönteminin uygulanmasında aşağıdaki aşamalar izlenmiştir:

- Ağaç diyagramı hazırlanırken analiz edilecek konu ve nedenler belirlenmiştir.

- İ́kinci aşamada katılımcıların öğrenci sorunlarının çözümlenmesine yönelik "Bu öğrenci sorunu nasıl çözülür?" sorusuna cevap aranmıştır. Beyin fırtınası yöntemiyle katılımcılar tarafından öneriler geliştirilmiştir. Konu ile ilgili ayrıntılar sağ tarafa doğru yazılmıştır. Cevapların gerekli ve yeterli olup olmadığı kontrol edilmiştir.

- Yeni bakış ve öneriler ortaya çıkmayana kadar bu aşamalara devam edilmiştir (Tague, 2005, 501-503).

Araştırmada uygulanan neden nasıl ağaç diyagramına tablo 1'de yer verilmiştir. 
Göktaş, P. (2015). Y kuşağı bakış açısıyla öğrenci sorunları ve çözüm önerileri: Isparta Meslek Yüksekokulu Örneği. International Journal of Social Sciences and Education Research, 1 (1), 197-206.

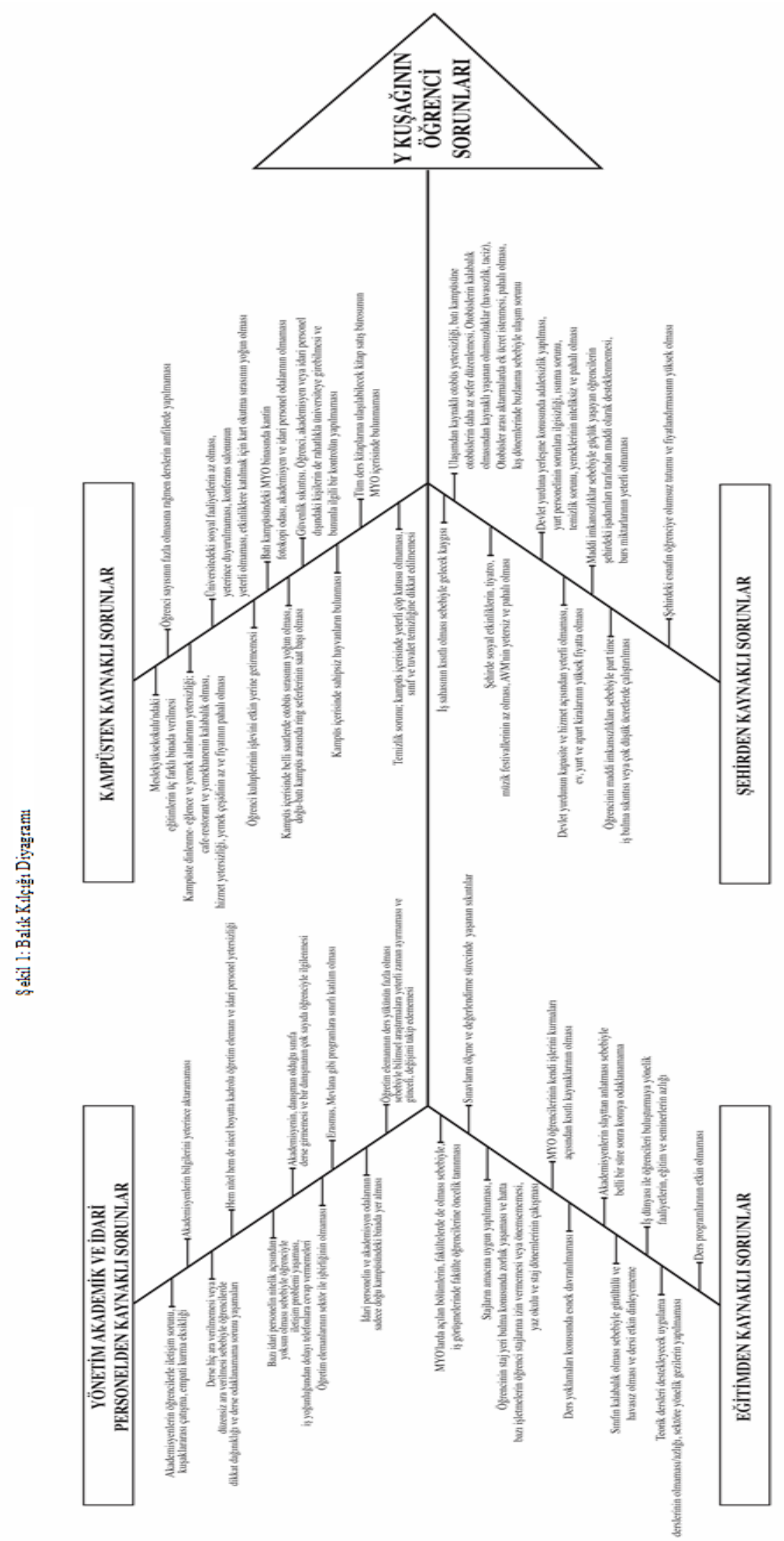


Göktaş, P. (2015). Student problems and solution proposals by generation Y perspective: Isparta Vocational High School Case. International Journal of Social Sciences and Education Research, 1 (1), 197-206.

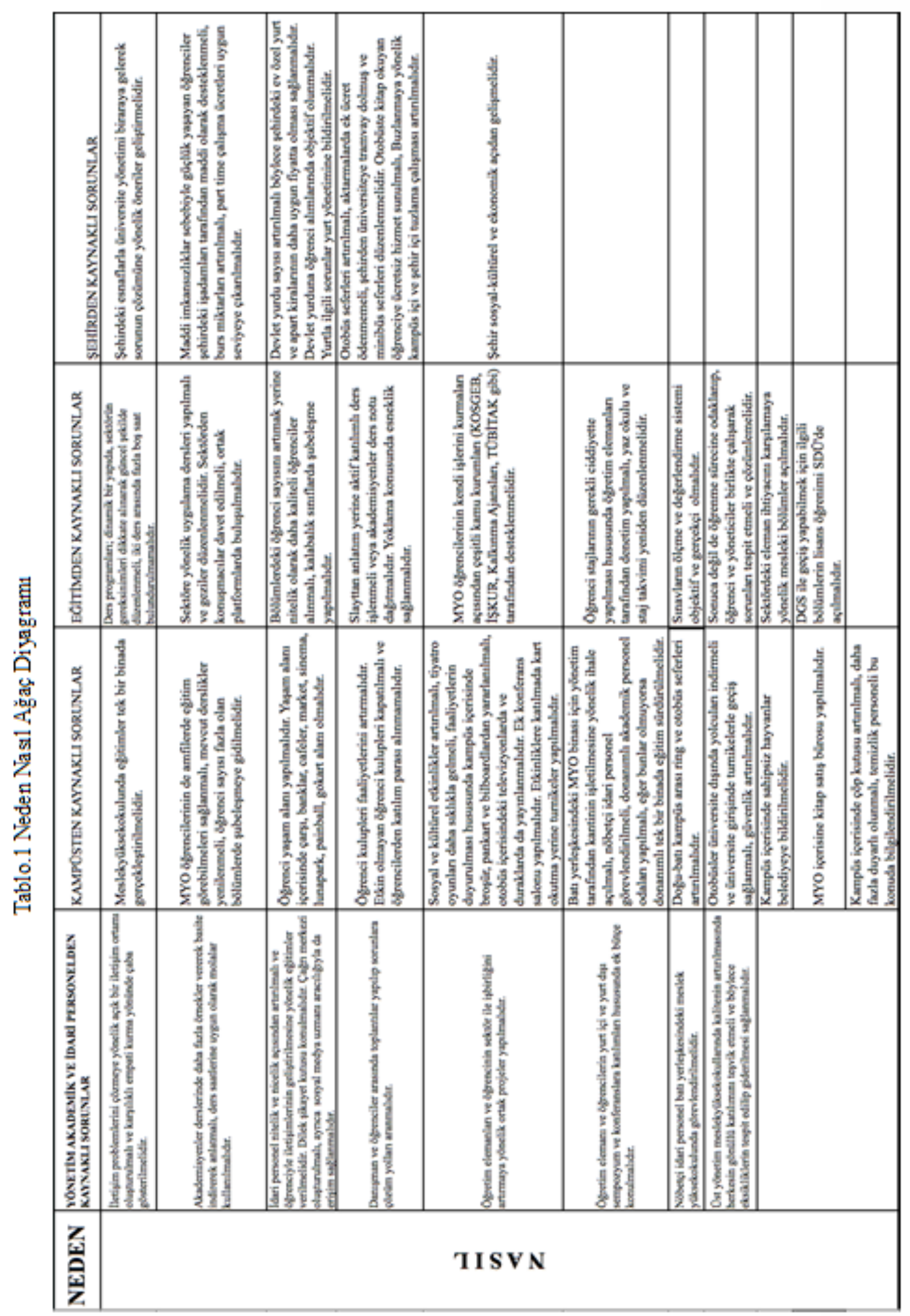


Göktaş, P. (2015). Y kuşağı bakış açısıyla öğrenci sorunları ve çözüm önerileri: Isparta Meslek Yüksekokulu

Örneği. International Journal of Social Sciences and Education Research, 1 (1), 197-206.

\section{Araştırma bulguları}

Bu çalışmada Balık kılçığı yöntemi aracılığıyla Süleyman Demirel Üniversitesi Isparta Meslek Yüksekokulu'nda öğrenim gören Y kuşağı öğrencilerinin sorunları ele alınmıştır. Öğrenci sorunları dört temel nedende irdelenmiştir. Bunlar; yönetim, akademik ve idari personelden kaynaklı sorunlar, kampüsten kaynaklı sorunlar, eğitimden kaynaklı sorunlar ve şehirden kaynaklı sorunlardır. Balık kılçığı diyagramıyla belirlenen bu sorunlara tablo 1'de gösterildiği gibi Neden Nasıl Ağaç diyagramı yöntemi aracılığıyla çözüm önerileri getirilmiştir.

$\mathrm{Bu}$ çalışmada elde edilen bulgulara paralel olarak literatür incelendiğinde;

Türkiye'de kurulan ilk meslek yüksekokulları arasında yer alan Çorum ilindeki Hitit Üniversitesi Meslek Yüksekokulu'nda yaşanan sorunlar ele alınmıştır (Alkan vd., 2014:133). Bunlardan bazıları; öğrenci sayısının artmasına rağmen meslek yüksekokullarının altyapı, mekan, donanım ve öğretim elemanı eksikliği, iş dünyası ile mesleki eğitim arasında koordinasyon eksikliği, ders programlarının etkin olmaması, stajların önemsenmesi, sektörle işbirliği olmaması gibi sorunlardır. Ayrıca 13 farklı çözüm önerileri dile getirilmiştir. Bunlardan bazıları şunlardır: eğitim teknolojilerinin kullanılması, nitelikli öğretim elemanı temini, çeşitli kamu kurumları tarafından desteklenme ve sektörel işbirliği sağlanmasıdır (Alkan vd., 2014: 136-139).

Mahiroğlu ve Buluç (1999)'un çalışmasında Türk eğitim sistemindeki sorunlardan bazılarını değişme ve gelişmeyi takip edememek, teknolojiyi yakalayamak, araç-gereç, personel ve kaynak yetersizliği, bilimsel araştırma faaliyetlerinin eksikliği ve nitelikli personel eksikliği olarak belirtmiştir (Mahiroğlu ve Buluç, 1999).

Ankara Üniversitesi Dikimevi Sağlık Hizmetleri Meslek Yüksekokulu öğrencilerinin kendi sağlık sorunlarıyla ilgili düşüncelerini ele alan çalışmada tespit edilen sorunlardan bazıları şunlardır: Ders programlarının ve staj takviminin etkili olarak düzenlenmemesi, üniversitedeki sosyal ve kültürel faaliyetlerin eksikliği, yurtların sayıca yetersizliği, yemeklerinin niteliksiz ve pahalı olması, temizlik sorunu, personelin ilgisizliği, okulun fiziksel koşullarının uygun olmaması, öğrenci işleri hizmetlerinin yavaş işlemesidir (Esatoğlu ve Köse, 2002: 9).

Toplam kalite yönetimi uygulamaları çerçevesinde Kırklareli Üniversitesi Meslek Yüksekokulu öğrenci memnuniyetiyle ilgili anket çalışması yapılmıştır. Bu çalışmanın sonucunda, sektöre yönelik bilgi ve deneyimleri arttıracak teknik gezilerin yapılmaması, iş dünyasını tanıtıcı sektörden konuşmacıların öğrencilerle buluşturulmaması ve bu çalışmada da edindiğimiz sonuçlardan biri olan teorik dersleri destekleyecek uygulama çalışmalarının yapılmaması gibi sorunlardan dolayı memnuniyet düzeylerinin düşük olduğu belirlenmiştir (İçli ve Vural, 2010: 348).

Meslek yüksekokullarında üniversite-sanayi işbirliğinin yerel bazda uygulama örneğini ele alan çalışmada meslek yüksekokullarında yetiştirilen ara meslek elemanlarının sanayi ve hizmet sektörü ile uyumlu ve karşılıklı arz talep dengesini sağlayacak modellerin yerel bazda uygulanması ile yöresel kalkınmaya olumlu etkisi olacağı belirtilmiştir (Sevim ve Karamete, 2003: 1).

Sakarya Meslek Yüksekokulunun sektör işbirliği bağlamında bir mesleki yükseköğretim modelinin analiz edildiği çalışmada bu model ile öğrencilerin uygulama eksiklikleri giderilmeye çalışılmıştır (Sarıaltın ve Erol, 2015: 68).

Türker (2003)'in çalışmasına göre yükseköğretimde kalitenin artırılması için açık bir iletişim ortamı oluşturulması, ölçme ve değerlendirme sisteminin gerçekçi olması, akademik ve idari tüm kadroların katılımıyla üst yönetimin desteği gibi önerilerde bulunulmuştur. İncelenen araştırma 
Göktaş, P. (2015). Student problems and solution proposals by generation Y perspective: Isparta Vocational High School Case. International Journal of Social Sciences and Education Research, 1 (1), 197-206.

bulgularına göre meslek yüksekokullarındaki sorunlar ve çözüm önerilerinin yapılan bu çalışma ile paralellik gösterdiği tespit edilmiştir.

\section{Sonuç ve öneriler}

Meslek yüksekokullarında yaşanan birçok sorun nedeniyle Türkiye rekabet gücünü artırma ve ekonomik büyüme hususunda tam olarak gelişme gösterememektedir. Burada dikkat edilmesi gereken meslek yüksekokullarının önemine inanmak, sorunları belirlemek ve çözüm üretmektir (Alkan vd., 2014: 136). Bu çalışmada mesleki eğitimin en önemli bileşenlerinden olan meslek yüksekokullarının sorunları Y kuşağında yer alan öğrencilerin bakış açısıyla ele alınmıştır.

Y kuşağında yer alan öğrencilerin bakış açısıyla öğrenci sorunlarına yönelik ifadelerin yer aldığı bu çalışmaya Süleyman Demirel Üniversitesi Isparta Meslek Yüksekokulu'ndan kolayda örneklemi yöntemiyle seçilen 350 öğrenci katılmıştır. Kalite araçlarından beyin firtınası tekniği kullanılarak sorunlar ve çözüm önerileri ile ilgili öğrencilerin düşünceleri alınmıştır. Fikirler değerlendirilerek balık kılçığı diyagramında ana sorunlar saptanmıştır. Ana sorunların çözümü için Neden Nasıl ağaç diyagramı oluşturulmuştur. Oldukça önemli olan ve çözüm gereken sorunlar; yönetim, akademik ve idari personelden kaynaklı sorunlar, kampüsten kaynaklı sorunlar, eğitimden kaynaklı sorunlar ve şehirden kaynaklı sorunlar olup bu sorunların alt nedenleri belirtilmiştir.

Sorunların çözümü için; Y kuşağında yer alan öğrencilerin çözüm önerileri dikkate alınarak konusunda uzman olmakla birlikte her zaman öğrenmeye yeniliklere, gelişime açık, disiplin kurarken tüm öğrencilerine ilgi gösteren, dersinde düzen sağlayan, sorun yaratmayan, sorunları çözen, öğrencilerine etik değerleri ve davranışı kazandıran, uygulayan uygulatan, sıfır hatayı hedefleyen eğitimcilerin olması gerekmektedir. Akademisyenlerin ve yöneticilerin öğrencilere bilgiyi bulmayı ve öğrenmeyi öğretmenin yanı sıra onların duygusal ve sosyal gereksinmelerine eğilip onlara bu konularda gereken sosyal ve kültürel desteği vermeleri gerekir. Bu tür aktivitelere katılma ve düzenlemeye yönelik maddi manevi destek sağlanmalıdır. Ayrıca sosyal ve kültürel faaliyetler iş sahasının kısıtlanmamasında da önemli rol üstlenmektedir. Meslek Yüksekokullarının işlevlerini topluma göstermek adına MYO'larla ilgili tanıtım filmleri hazırlanmalıdır. Meslek yüksekokulları tarafından halka açı yerlerde sergilenerek toplumla bütünleşme sağlanabilmelidir. Yapılan bu çalışmanın yönetimin merkeziyetçilikten uzaklaşarak öğrenci odaklı bir yaklaşım benimsemeleri, mevcut durum ve sorunların tespit edilmesinde, öneriler geliştirilmesinde öğrencilerin görüşleri alınarak, onlara değerli olduklarını hissettirerek, takım ruhunu geliştirerek motivasyonlarının artırılması ve böylece bilimsel düşünebilen bireyler olarak gelişebilmeleri hususlarında katkı sağlaması beklenmektedir. Sonuç olarak Y kuşağı tarafından geliştirilen öneriler başta üst yönetim ile paylaşılmalı ve öğrencilerin farklı görüş ve beklentilerine önem verilerek eğitimde düzenleme ve iyileşmelere gidilmelidir. Bu sorunlar dikkate alındığında, Y kuşağında yer alan meslek yüksekokulu öğrencilerinin sorunlarının çözülerek nitelikli bir eğitim sürecinden geçerek mezun olmaları ve aynı zamanda toplumsal gereksinimlerin karşılanması mümkün olabilecektir.

\section{Kaynakça}

Alkan, R. M., Suiçmez, M., Aydınkal, M. Ve Şahin, M., (2014). Meslek Yüksekokullarındaki Mevcut Durum: Sorunlar ve Bazı Çözüm Önerileri, Yükseköğretim ve Bilim Dergisi /Journal of Higher Education and Science, 4(3), 133-140.

Baykara, S., (1999). “Eğitimde Toplam Kalite Yönetimi'nin Uygulanabilirliği ve Bir Model Önerisi”, Yüksek Lisans Tezi, Afyon Kocatepe Üniversitesi, Sosyal Bilimler Enstitüsü. 
Göktaş, P. (2015). Y kuşağı bakış açısıyla öğrenci sorunları ve çözüm önerileri: Isparta Meslek Yüksekokulu Örneği. International Journal of Social Sciences and Education Research, 1 (1), 197-206.

Cresswell, J. W. (2013). Araştırma Deseni: Nitel, Nicel ve Karma Yöntem Yaklaşımları (S. B. Demir, Çev.), Ankara: Eğiten Kitap.

Esatoğlu, A. E. ve Köse, A., (2002), “Ankara Üniversitesi Dikimevi Sağl1k Hizmetleri Meslek Yüksekokulu Öğrencilerinin Kendi Sağlık Sorunlarıyla İlgili Düşünceleri”, Ankara Üniversitesi Dikimevi Sağllk Hizmetleri Meslek Yüksekokulu Yıllı̆̆ $, 3(1), 7-12$.

İçli, G. E. ve Vural, B. B., (2010). “Toplam Kalite Yönetimi ve Uygulamaları Çerçevesinde Kırklareli Üniversitesi Meslek Yüksekokulları Öğrenci Memnuniyeti Araştırması”, Marmara Üniversitesi İIBF Dergisi, XXVIII (I), 335-349.

Kuşak Kavramı, (2014). http://www.tdk.gov.tr/index.php?option=com _gts\&arama= gts\&guid=TDK.GTS.5408f7540958c9.20724491, (Erişim Tarihi: 30.01.14).

Kyles, D., (2005). “Managing Your Multigenerational Workforce”, Strategic Finance, 87 (6), ss.53-55.

Mahiroğlu, A. ve Buluç, B., (1999). "Eğitimde Toplam Kalite Yönetimi ve Kalite Yönetiminin Araçları", Politeknik Dergisi, 2(1), 53-61.

Parry, E., ve Urwin, P., (2011), "Generational Differences in Work Values: A Review of Theory and Evidence", International Journal of Management Reviews, 13, ss.79-96.

Sarıaltın, H. ve Erol, Z., (2015). "Meslek Yüksekokulu (MYO) Sektör İşbirliği Bağlamında Bir Mesleki Yükseköğretim Modelinin Analizi (Sakarya Üniversitesi 3+1 Modeli)”, www.ejoir.org Özel Say1, 5669.

Sevim, S. ve Karamete, F., (2003). "Meslek Yüksekokullarında Üniversite-Sanayi İşbirliği, Yöresel Kalkınmaya Etkisi ve Yerel Bazda Uygulama Örneği”, Dumlupınar Üniversitesi Sosyal Bilimler Dergisi, 5(8), 1-18.

Tague, N. R. (2005). The Quality Toolbox, 2. Bask1, Milwaukee Wisconsin:ASQ Quality Press

Türker, R., (2003). “Yüksek Öğretimde Kalite”, Bilim Eğitim ve Düşünce Dergisi, 3(4), ss.11.

Uz, O., (2014). “Eyvah Y Kuşağı!”, İndigo Dergisi, Sayı:95, http://indigodergisi.com/ 2013/08/eyvah-ykusagi/, (Erişim Tarihi: 01.06.2014). 
Göktaş, P. (2015). Student problems and solution proposals by generation Y perspective: Isparta Vocational High School Case. International Journal of Social Sciences and Education Research, 1 (1), 197-206.

\section{Extended abstract in English}

Almost born in the same year, the group of individuals with common characteristics can be defined as the generation. Generation classification is made as Traditionalists, the Baby Boomers, Gen X, Y and Z. Traditionalists covers people born between the 1900's and the year 1945. The Baby Boomers covers people born between the 1946's and the year 1964. Generation Xers covers people born between the 1965's and the year 1979. Generation Y covers people born between the 1980's and the year 1999. Generation Z covers people born after the year 2000.

As part of this research, student's problems were researched for the Y Generation who was born between 1980-1999. These problems have been identified with brain storming method, have been analysed with fishbone diagram and solution proposals have been presented by why-how tree diagram according to studens' view of Süleyman Demirel University Isparta Vocational High School. This research is aimed to improve the quality of education.

Süleyman Demirel University Isparta Vocational High School has seven departments and 5570 students. These departments are; management and organization, foreign trade, accounting and taxation department, design department, hotel restaurant and catering services department, marketing and advertising department, finance banking and insurance department. 50 student have been selected from each of the seven departments in other words a total of 350 students of Süleyman Demirel University Isparta Vocational High School participated in this research.

Firstly students' problems have been identified with brainstorming method. Brainstorming method is preferred because of generating a large number of creative ideas in a short period of time. According to this method, all ideas are recorded and there are no stupid ideas, no criticism, no evaluation and no discussion of ideas. Then problem has been reviewed to be discussed, every students has been thought about their problems. All ideas has been written on the board. No discussion or evaluation of any kind is permitted. That has been continued generate and record ideas until several minutes' silence produces no more. So students said their ideas without hesitation by using brainstorming method.

Secondly students' problems have been analysed with fishbone diagram. The fishbone diagram is also called cause and effect diagram or Ishikawa diagram. "Student problems by generation Y perspective" has been written at the center right of the whiteboard, then has been drawen a box around it and drawen a horizontal arrow running to it. In the fishbone diagram, many possible causes are identified for student problems by Generation Y perspective in Süleyman Demirel University Isparta Vocational High School. The fishbone diagram used to structure a brainstorming session and so ideas sorted into useful categories. The ideas obtained through the method of brainstorming were divided into four categories. These four categories are; Problems about manager, academic staff and administrative staff, problems about campus, problems about education, problems about city (Isparta).

Then the categories of causes as branches from the main arror has been written. When students run out of ideas, the fishbone diagram is completed. Some of students' problems are;

1-Problems about manager, academic staff and administrative staff: communication issues, lack of empathy, intergenerational conflict, lack of academic and administrative staff, not to break the course, inability to transfer the knowledge, limited participation for Erasmus and Mevlana programs, the lack of cooperation with academic staff and sector managers, 
Göktaş, P. (2015). Y kuşağı bakış açısıyla öğrenci sorunları ve çözüm önerileri: Isparta Meslek Yüksekokulu Örneği. International Journal of Social Sciences and Education Research, 1 (1), 197-206.

2- Problems about campus: training carried out in three different buildings, having a greater number of students but lack of amplifier, lack of entertainment area, lack of cafe restaurant, lack of food service, lack of social activities, security problem, lack of book store.

3- Problems about education: course schedules, lack of practical courses, lack of seminar and symposium, crowded classes, internship issues.

4- Problems about city (Isparta): the negative attitude of shopkeepers, lack of social activities, small shopping center, high rent-apartments and transportation issues.

Thirdly, solution proposals have been presented by why-how tree diagram according to studens' view of Süleyman Demirel University Isparta Vocational High School. Tree diagram is also called systematic diagram, tree analysis, analytical tree and hierarchy diagram. This diagram have been used for solving students' problems which have been identified with brainstorming method and have been analysed with fishbone diagram. Often it is the best phrased "how" question. Students have been thought about "how this problem can be solved" and then they have been begun to generate ideas. Thus solution proposals about students' problems in Süleyman Demirel University Isparta Vocational High School have been made. Some of solution proposals are; empathy, positive communication environment, coordination with sector managers, common projects, seminars, symposiums, support from top management, bazaar, market, go-kard area, paintball area, cinema should be taken placed in campus. These students' problems and solutions proposals should be shared with university management and local authorities, so that the quality of education is expected to improve. It would make important contributions if new researchers study about particularly the characteristics of generations in Turkey. 